\title{
IMPACTOS DA URBANIZAÇÃO BRASILEIRA E O DIREITO DE PROPRIEDADE
}

IMPACTS OF BRAZILIAN URBANIZATION AND PROPERTY LAW

\section{Marco Aurelio Zazyki}

Doutor em Administração pela Universidade Federal de Santa Maria (Santa Maria/Brasil). Professor no Departamento de Administração e Ciências Contábeis da Faculdade Centenário Metodista (Santa Maria/Brasil).

E-mail: zazyki@hotmail.com

\section{Solange Marin}

Doutora em Desenvolvimento Econômico pela Universidade Federal do Paraná (Curitiba/Brasil). Professora no Programa de Pós-Graduação em Economia/Centro Sócio-Econômico da Universidade Federal de Santa Catarina (Florianópolis/Brasil).

E-mail: solmarin@gmail.com

\section{Gilnei Luiz de Moura}

Doutor em Administração pela Universidade de São Paulo (São Paulo/Brasil). Professor no Programa de Pós-Graduação em Administração/Centro de Ciências Sociais Humanas - PPGA/CCSH da Universidade Federal de Santa Maria (Santa Maria/Brasil).

E-mail:mr.gmoura.ufsm@gmail.com

Recebido em: 17 de março de 2020

Aprovado em: 23 de junho de 2020

Sistema de Avaliação: Double Blind Review

RGD | v. 17 | n. 3 | p. 34-55 | set./dez. 2020

DOI: https://doi.org/10.25112/rgd.v17i3.1993 


\section{RESUMO}

O artigo analisa os impactos causados pelo processo de urbanização nacional relacionados à moradia, com base nos estudos de Douglass North, da Nova Economia Institucional (NEI). A metodologia é caracterizada por um estudo exploratório a partir de uma revisão de literatura referente ao processo de urbanização brasileiro e a abordagem sobre o direito de propriedade sob a perspectiva da teoria economia institucionalista. Os resultados teóricos e empíricos acumulados pela NEI oferecem um instrumental importante para uma melhor compreensão das várias interfaces entre o sistema econômico e as instituições legais e jurídicas que condicionam as atividades e transações econômicas relacionadas à moradia. As ideias de North mostraram-se adequadas na discussão do tema, haja vista que se o direito de propriedade for mais bem definido, atribuído e garantido, nessas comunidades, menores serão os custos de transação e, consequentemente, maior será o valor do ativo e da renda do proprietário deste.

Palavras-chave: Urbanização brasileira. Dinâmica populacional. Direito de propriedade urbano.

\section{ABSTRACT}

The article analyzes the impacts caused by the process of national urbanization related to housing, based on Douglass North studies of the New Institutional Economics (NEI). The methodology is characterized by an exploratory study based on a literature review regarding the Brazilian urbanization process and the approach on property rights from the perspective of institutionalist economics theory. The theoretical and empirical results accumulated by the NEI provide an important tool for a better understanding of the various interfaces between the economic system and the legal and juridical institutions that condition the economic activities and transactions related to housing. The ideas of North were adequate in the discussion of the subject, since if the property rights are better defined, assigned and guaranteed in these communities, the lower the transaction costs and, consequently, the greater the value of the asset and of the owner's income.

Keywords: Brazilian urbanization. Population dynamics. Urban property rights. 


\section{INTRODUÇÃO}

A pobreza urbana e os problemas envolvendo moradia são um fenômeno mundial crescente. Quase um bilhão de pessoas, ou seja, um sexto da população mundial vive em favelas urbanas ou assentamentos informais. Os dados estão no relatório da Organização das Nações Unidas - ONU (United Nations, 2018) divulgado na Conferência das Nações Unidas sobre Moradia e Desenvolvimento Urbano Sustentável, a Habitat 3, ocorrida no Equador em outubro de 2016, criada para debater mundialmente temas afeitos à habitação e ao desenvolvimento urbano.

A dinâmica populacional, fruto da rápida urbanização, especialmente nos países em desenvolvimento, pode se percebida pelo resultado do último censo demográfico do Instituto Brasileiro de Geografia e Estatística (IBGE) (2010), onde a população urbana do Brasil correspondia a 84,4\% e que parcela expressiva desse contingente populacional residia nas principais regiões metropolitanas. Um dado alarmante, disponibilizado pelo Instituto no mesmo ano, é de que cerca de 11 milhões de habitantes vivem em moradias inadequadas, como favelas e invasões, o que equivale a aproximadamente 6\% da população, o que lamentavelmente vem a corroborar os dados da ONU supracitados. Porém, afirmar que ingressamos em uma sociedade urbana vai além da sua expressão demográfica.

A favelização é a expressão mais acentuada dos problemas de moradia no Brasil, uma vez que, em maior parte, é formada por pessoas que não dispõem de condições sociais e financeiras de acessarem o mercado formal de moradia e acabam por construir suas habitações em áreas impróprias, muitas vezes de risco ou não recomendadas, com o agravante de não terem acesso a serviços públicos básicos. Essa realidade pôde ser percebida no fatídico desastre ocorrido em maio de 2018, em que cerca de 150 famílias, que habitavam de forma irregular um prédio público abandonado na cidade de São Paulo, perderam o pouco que tinham após um incêndio seguido de um desabamento. Esse exemplo traz à tona as carências e contradições existentes no espaço urbano brasileiro relativas à moradia, expressas espacialmente com o processo de favelização e invasões.

A Nova Agenda Urbana consagra uma nova visão da urbanização como motor indispensável para o desenvolvimento e pré-requisito para a prosperidade e o crescimento. É graças a essa mudança de paradigma que a urbanização e o desenvolvimento estão ligados inseparavelmente. Assim, urge que a titularização da propriedade urbana seja compreendida como um desafio institucional para promoção do desenvolvimento das cidades e enfrentamento das necessidades habitacionais dos mais pobres e mais vulneráveis, especialmente mulheres, jovens e aqueles que vivem em favelas.

Posta essa realidade, torna-se relevante investigar esse tema, mesmo que de forma reflexiva, visto o momento de mobilização nacional e internacional ainda ser oportuno para se reafirmar o lugar central 
das cidades e do desenvolvimento urbano, para que as cidades sejam cada vez mais espaços de equidade,

\section{inclusão, justiça socioambiental e bem-estar.}

O futuro sustentável das cidades e os benefícios da urbanização dependem fortemente de abordagens futuras à moradia, e uma possível explicação para essa situação pode surgir da análise da relação do processo de urbanização e o direito de propriedade. Esse artigo teórico-empírico pretende investigar a relação entre o processo de urbanização brasileiro e o direito de propriedade. Para tanto, o método adotado nessa pesquisa exploratória se assenta em duas etapas: (i) uma revisão de literatura sobre o processo de urbanização brasileiro e o direito de propriedade para a construção de uma contextualização para o problema; e (ii) uma análise das possibilidades presentes na literatura consultada para a concepção do referencial teórico da pesquisa, com o propósito de reconhecer como o tema é tratado por outras perspectivas e organizar informações sobre a realidade econômica e político-social brasileira.

\section{O BRASIL URBANO: AS CIDADES QUE TEMOS}

Esta seção apresenta os aspectos gerais da urbanização brasileira, suas nuances referentes mais detalhadamente à sua dinâmica populacional e os impactos deste processo.

\subsection{DINÂMICA POPULACIONAL}

A partir da revolução industrial, o fenômeno de urbanização se alastrou pelas cidades mundiais. Milton Santos (2008) aponta que o início da urbanização no Brasil data desde o século XVI, mas, em seu começo, tratava-se mais da criação de cidades do que propriamente urbanização. O acelerado processo de urbanização no Brasil, muito superior ao dos países desenvolvidos, foi uma notável novidade. O Censo de 1970 registrava pela primeira vez que, durante os anos sessenta, a população urbana tinha superado a rural. Do ponto de vista histórico, trata-se de um fenômeno recente. Entretanto, neste curto espaço de tempo, a segunda metade do século passado, a população urbana passou de 19 milhões para 138 milhões de habitantes, com uma taxa de crescimento média anual de 4,1\%.

A cada ano, em média, foram acrescidos 2.378.291 habitantes às cidades, o que resulta que a população urbana, em meio século, apenas, aumentasse 7,3 vezes (Tabela 1). No período inicial do processo de urbanização acelerado, as taxas de fecundidade ainda estavam relativamente altas e, certamente, foram fundamentais para esse ritmo, apesar do seu declínio ter se iniciado logo na segunda metade da década de sessenta. As migrações internas contribuíram consideravelmente para a grande aceleração do processo de urbanização. Carvalho (2003) estima que, entre 1960 e o final dos anos oitenta, 
auge do ciclo migratório, saíram do campo para as cidades quase 43 milhões de pessoas, considerando, inclusive, os "efeitos indiretos da migração", ou seja, os filhos tidos pelos migrantes rurais nas cidades.

Tabela 1

Brasil, população total e urbana, grau de urbanização e incremento médio anual da população urbana, 1940-2010.

\begin{tabular}{ccccc}
\hline Período & Total & Urbana & Grau de Urbanização & Incremento \\
\hline $\mathbf{1 9 4 0}$ & 41.236 .315 & 12.880 .182 & 31.24 & - \\
$\mathbf{1 9 5 0}$ & 51.944 .397 & 18.782 .891 & 36.16 & 590.271 \\
$\mathbf{1 9 6 0}$ & 69.930 .293 & 31.214 .700 & 44.64 & 1.243 .181 \\
$\mathbf{1 9 7 0}$ & 93.139 .037 & 52.084 .984 & 55.92 & 2.087 .144 \\
$\mathbf{1 9 8 0}$ & 119.502 .716 & 80.436 .419 & 67.31 & 2.835 .144 \\
$\mathbf{1 9 9 1}$ & 146.825 .475 & 110.990 .990 & 75.59 & 2.777 .688 \\
$\mathbf{2 0 0 0}$ & 169.544 .443 & 137.697 .439 & 81.22 & 2.967 .383 \\
$\mathbf{2 0 1 0}$ & 190.755 .799 & 160.925 .792 & 84.36 & 2.322 .835 \\
\hline
\end{tabular}

Fonte: FIBGE, Censos Demográficos de 1940, 1950, 1960, 1970, 1980, 1991, 2000 e 2010.

A velocidade do processo de urbanização pode ser melhor visualizada nas Figuras 1 e 2 . $\mathrm{Na}$ primeira, destaca-se que a população urbana cresceu a taxas superiores a $4 \%$ ao ano durante três décadas seguidas, ou seja, entre 1950 e 1980. Entre 1950 e 1970 elas estiveram acima de 5\%, quando começaram a decrescer acentuadamente, chegando à primeira década do século XXI com uma taxa de 1,7\%. Um patamar relativamente baixo no seu ritmo histórico de crescimento.

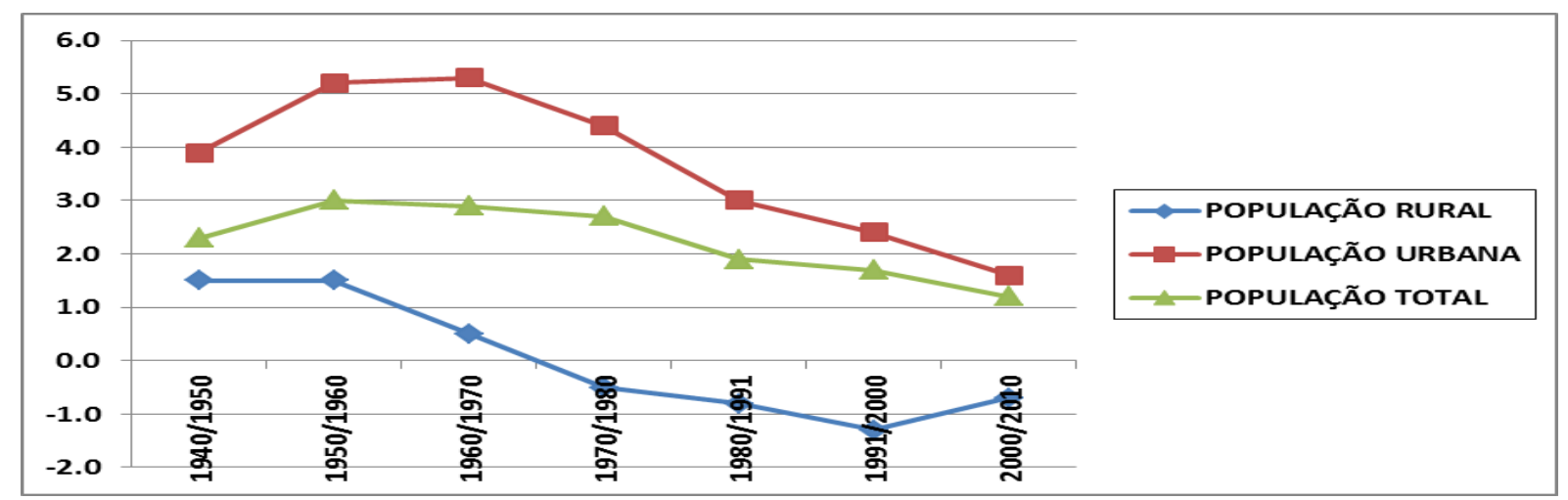

Figura 1. Brasil, taxa de crescimento anual da população total, urbana e rural (\%), 1940-2010. Fonte: FIBGE, Censos Demográficos de 1940, 1950, 1960, 1970, 1980, 1991, 2000 e 2010.

Contudo, ao se visualizar a Figura 2, verifica-se que foi tamanha a velocidade do crescimento nas décadas anteriores, e, consequentemente, o estoque acumulado de população, que o incremento médio anual da população urbana se expandiu aceleradamente até a última década do século XX. Entre 2000 e 2010 houve uma redução do incremento médio para 2.322.835 habitantes, com a população urbana apresentando, pela primeira vez, uma tendência ao declínio no seu ritmo de crescimento absoluto. Mesmo 
assim, esse incremento ainda é notável, pouco abaixo daquele da segunda metade do século XX, apesar do impacto da fase atual da transição demográfica, com taxas de fecundidade abaixo do nível de reposição, assim como do acentuado declínio da migração rural-urbana.

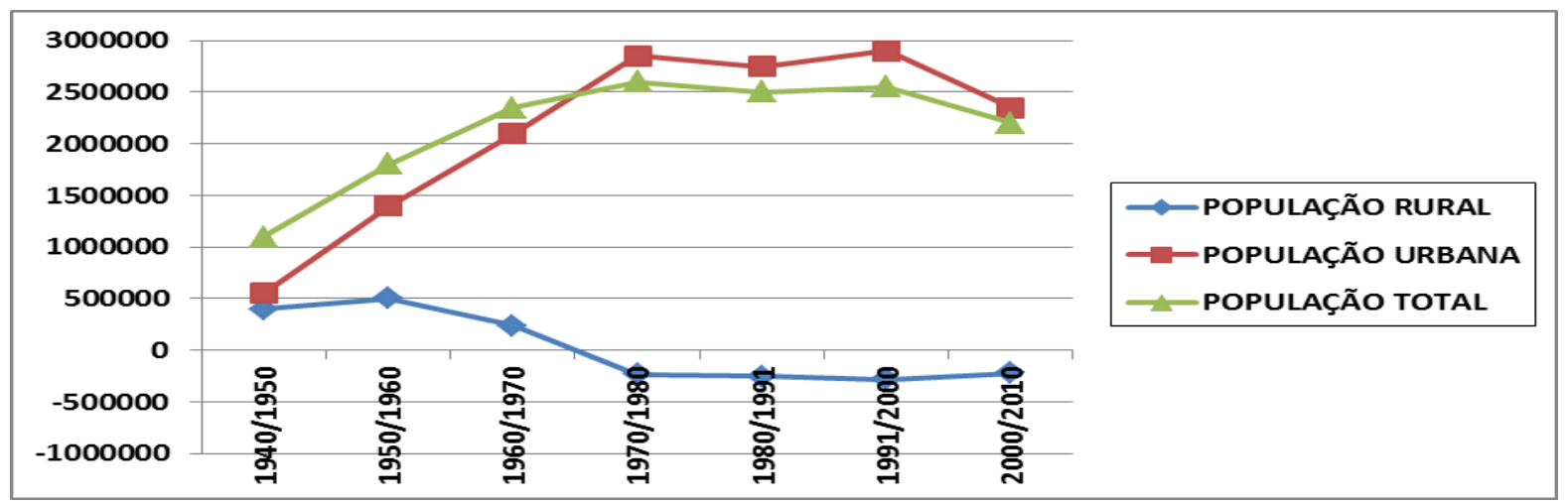

Figura 2. Brasil, incremento absoluto médio anual da população total, urbana e rural, 1940-2010.

Fonte: FIBGE, Censos Demográficos de 1940, 1950, 1960, 1970, 1980, 1991, 2000 e 2010.

Por sua vez, a população urbana residente tem uma distribuição diferenciada segundo o tamanho das cidades (Tabela 2). Ela tende a se concentrar nas cidades maiores do que 100.000 habitantes. Em 1940 e 1950, mais de 60\% da população urbana residia em cidades menores do que 100.000 habitantes, principalmente naquelas menores do que 20.000 habitantes. Já em 1970, quando o processo de urbanização começa a se acelerar, mais da metade da população residia em cidades maiores do que 100.000 habitantes, sendo que 34\% em cidades maiores do que 500.000 mil. Essa tendência à concentração da população urbana prevalece nos últimos dados censitários e pode ser considerada uma tendência estrutural da sociedade brasileira.

Tabela 2

Distribuição da população urbana segundo o tamanho das cidades, 1940-2010.

\begin{tabular}{ccccccccc}
\hline $\begin{array}{c}\text { Tamanho das } \\
\text { Cidades }\end{array}$ & $\mathbf{1 9 4 0}$ & $\mathbf{1 9 5 0}$ & $\mathbf{1 9 6 0}$ & $\mathbf{1 9 7 0}$ & $\mathbf{1 9 8 0}$ & $\mathbf{1 9 9 1}$ & $\mathbf{2 0 0 0}$ & $\mathbf{2 0 1 0}$ \\
\hline Até $\mathbf{2 0 . 0 0 0}$ & 46,82 & 38,78 & 33,77 & 26,92 & 21,36 & 19,34 & 18,81 & 17,13 \\
$\mathbf{2 0} \mathbf{a} \mathbf{5 0 . 0 0 0}$ & 9,41 & 13,01 & 11,61 & 12,04 & 11,40 & 12,44 & 11,49 & 11,83 \\
$\mathbf{5 0} \mathbf{a} \mathbf{1 0 0 . 0 0 0}$ & 7,65 & 8,86 & 9,57 & 7,80 & 10,50 & 10,23 & 10,57 & 9,93 \\
$\mathbf{1 0 0} \mathbf{a} \mathbf{5 0 0 . 0 0 0}$ & 14,55 & 13,43 & 16,06 & 19,59 & 21,92 & 24,43 & 26,11 & 27,34 \\
$>\mathbf{5 0 0 . 0 0 0}$ & 21,57 & 25,92 & 29,00 & 33,65 & 34,83 & 33,55 & 33,01 & 33,78 \\
$>\mathbf{1} \mathbf{0 0 0} \mathbf{0 0 0}$ & 36,12 & 39,36 & 45,05 & 53,24 & 56,75 & 57,98 & 59,12 & 61,12 \\
\hline
\end{tabular}

Total Absoluto $12.878 .647 \quad 18.775 .779 \quad 31.867 .324 \quad 52.097 .26080 .437 .327 \quad 110.990 .990137 .953 .959160 .925 .792$

Fonte: FIBGE, Censos Demográficos de 1940, 1950, 1960, 1970, 1980, 1991, 2000 e 2010. 
Os dados também revelam que há certa estabilidade na proporção de residentes em cidades maiores do que 500.000 habitantes, desde 1970, e um aumento na porcentagem dos residentes nas cidades entre 100 e 500.000 habitantes. A análise fica encorpada se forem considerados os residentes nos diferentes tamanhos de cidade para o incremento absoluto anual da população urbana (Tabela 3).

Tabela 3

Contribuição dos residentes nas cidades, segundo o tamanho, para o incremento da população urbana total, 1940-2010.

\begin{tabular}{ccccccccc}
\hline Tamanho das cidades & $\mathbf{1 9 4 0 / 5 0}$ & $\mathbf{1 9 5 0 / 6 0}$ & $\mathbf{1 9 6 0 / 7 0}$ & $\mathbf{1 9 7 0 / 8 0}$ & $\mathbf{1 9 8 0 / 9 1}$ & $\mathbf{1 9 9 1 / 2 0 0 0}$ & $\mathbf{2 0 0 0 / 2 0 1 0}$ \\
\hline Até $\mathbf{2 0 . 0 0 0}$ & 21,23 & 26,58 & 16,13 & 11,13 & 14,05 & 16,63 & 6,98 \\
$\mathbf{2 0}$ a $\mathbf{5 0 . 0 0 0}$ & 20,85 & 9,61 & 12,72 & 10,21 & 15,19 & 7,59 & 13,89 \\
$\mathbf{5 0} \mathbf{~} \mathbf{1 0 0 . 0 0 0}$ & 11,48 & 10,59 & 5,01 & 15,46 & 9,53 & 11,98 & 6,03 \\
$\mathbf{1 0 0}$ a $\mathbf{5 0 0 . 0 0 0}$ & 10,99 & 19,82 & 25,16 & $\mathbf{2 6}, 19$ & 31,04 & 33,05 & 34,69 \\
$\mathbf{>} \mathbf{5 0 0 . 0 0 0}$ & 35,44 & 33,40 & 40,97 & 37,02 & 30,19 & 30,75 & 38,41 \\
$\mathbf{> 1 0 0 . 0 0 0}$ & 46,44 & 53,22 & 66,14 & 63,21 & 61,23 & 63,80 & 73,10 \\
\hline Total & 100,00 & 100,00 & 100,00 & 100,00 & 100,00 & 100,00 & 100,00 \\
\hline
\end{tabular}

Fonte: FIBGE, Censos Demográficos de 1940, 1950, 1960, 1970, 1980, 1991, 2000 e 2010.

Na ultima década, a população residente em cidades maiores do que 100.000 habitantes era responsável por $73 \%$ do crescimento da população urbana, um nível superior àquele encontrado nos anos sessenta, no início da aceleração do processo de urbanização. Essas variações refletem a crescente participação dos residentes nas cidades entre 100 e 500.000 habitantes que, desde os anos oitenta, passaram a ter uma contribuição relativa um pouco superior ao grupo de cidades com população superior a 500.000.

Uma conclusão preliminar é que o acelerado processo de urbanização no Brasil, alimentado pela maciça migração rural-urbana, tem sido, desde o seu início, não só acelerado, mas concentrador da população em cidades maiores do que 500.000 habitantes, com uma relativa tendência recente favorável às cidades médias, ou seja, aquelas entre 100 e 500.000. (Figura 3).

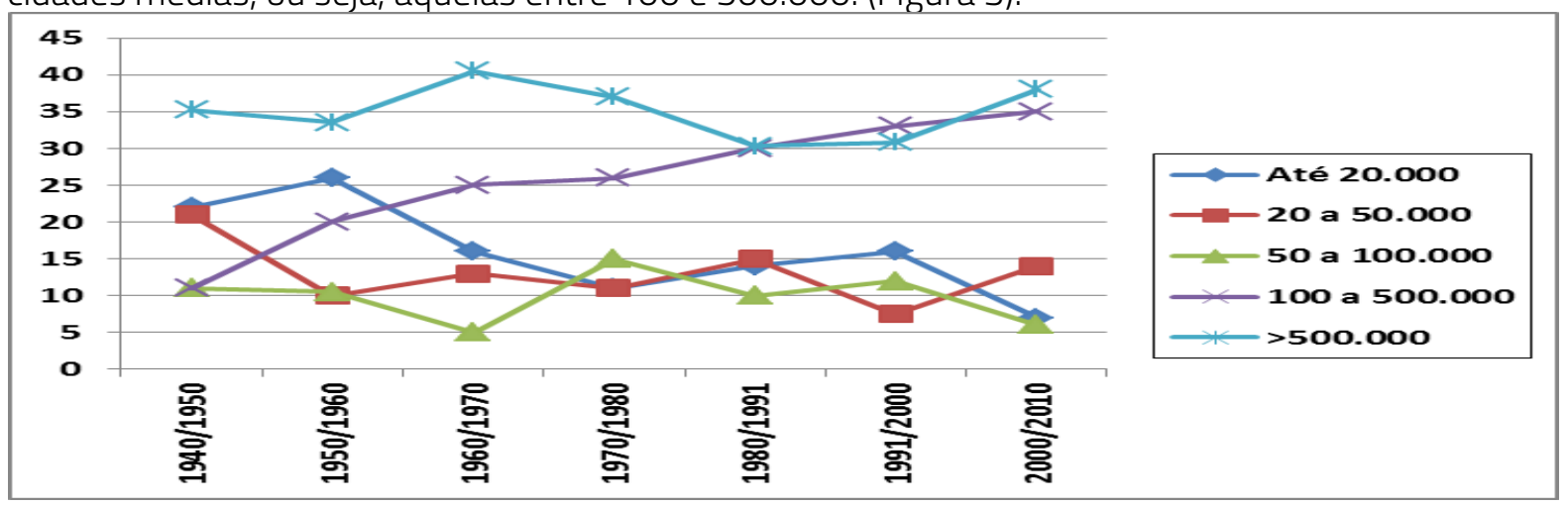

Figura 3. Brasil, contribuição da população urbana segundo o tamanho das cidades para o crescimento da população urbana total (\%), 1940-2010.

Fonte: FIBGE, Censos Demográficos de 1940, 1950, 1960, 1970, 1980, 1991, 2000 e 2010. 
Até o momento, foi possível se identificar a dinâmica populacional brasileira, fruto de um crescimento rápido e desordenado. Na próxima subseção apresentaremos as consequências relacionadas à moradia causadas pela urbanização no Brasil.

\subsection{IMPACTOS DA URBANIZAÇÃO}

O processo de urbanização tem a transição urbana como dimensão marcante, visto que esta envolve a passagem para a predominância da população urbana em determinado espaço, com enfoques diferenciados conforme a sociedade que se esteja considerando. Autores como Ojima (2006) e Silva e Monte-Mór (2010) apontam, em linhas gerais, que a transição urbana teria duas fases, uma primeira transição urbana seria o momento em que a população urbana supera a população rural e o grau de urbanização se eleva de maneira sustentada. 0 que se entende como segunda transição urbana deriva do fato de que as tendências de crescimento populacional urbano perdem sua força para dar lugar à luta da população para se localizar dentro de seu tecido urbano e garantir seu acesso aos serviços, bens e oportunidades da cidade. Nessa perspectiva, a primeira transição representaria uma dimensão mais quantitativa do processo de urbanização, enquanto a segunda a uma dimensão mais qualitativa.

A primeira das fases seria articulada à primeira transição urbana, por meio de uma pressão demográfica intensa via migrações e fecundidade alta, que levam a população urbana a ser a maioria e tem como consequência uma produção urbana descontrolada, uma lógica da desordem (KOWARICK, 1979). Autoconstruções, invasões, a luta por espaço para moradia e melhorias nos serviços públicos seriam questões essenciais. A fase mais recente de urbanização, conforme Portes e Roberts (2005) se caracteriza por uma menor pressão demográfica, mas com uma diversificação de demandas, que resultariam em lutas e pressões sociais pelo aprofundamento de direitos em uma lógica de produção do espaço urbano controlado pelo mercado, ainda que com importante apoio estatal, no qual a segregação socioespacial se ampliaria. Nesse sentido, é possível afirmar que mais da metade da população das grandes cidades está vivendo em habitações que se encontram fora dos padrões legais (ROLNIK, 2009).

Devido a esse volume de assentamentos informais, formaram-se dois tipos de cidade e cidadão: o formal e o informal. A este, por não estar enquadrado nos ditames legais, o poder público, por muitos anos, esquivou-se de fornecer o mínimo de infraestrutura necessária para a obtenção de habitações salubres. Já àquele, foram até mesmo criadas leis específicas para a sua melhor regulamentação. Esta exclusão territorial ensejou a segregação social da população residente dessas áreas. Fato que contribui para o quadro de pobreza e miséria no Brasil. Além do descumprimento de um direito social - o direito à moradia - os efeitos desta exclusão vão além da esfera dos habitantes destas áreas. Refletem-se no aumento na violência urbana, na emergência do mercado informal, bem como na contribuição para 
a degradação ambiental de maneira geral nas cidades, visto que, em muitos destes locais, inexistem serviços de saneamento básico e de coleta de lixo.

No Brasil, o modelo de industrialização e crescimento econômico do "desenvolvimentismo autoritário" (MANTEGA, 1997), a partir da década de 1960, baseado na concentração da renda como geradora de poupança e nos baixos salários como garantia de baixos custos da reprodução da força de trabalho (MARICATTO, 2001), promoveu uma matriz de urbanização marcada pela desigualdade social e o não atendimento à demanda habitacional por parte da população de baixa renda. A urbanização brasileira ocorreu baseada na diferenciação econômica dos espaços urbanos e na segregação socioespacial. Em outras palavras, a urbanização das cidades brasileiras ocorreu de maneira rápida e excludente, e os resultados deste processo são visíveis hodiernamente.

Em 1940, a população urbana brasileira somava-se a 18,8 milhões de habitantes e, no ano de 2000, chegou a aproximadamente 138 milhões (MARICATTO, 2001), e cerca de 80\% da população brasileira residia nas cidades (FERNANDES, 2001). Este acelerado e não controlado processo acarretou uma série de problemas socioeconômicos para as urbes brasileiras. A população rural migrou para a cidade em busca de emprego e de melhores condições de vida. Todavia, em face da legislação, do mercado de terras e de políticas elitistas, a grande parcela com baixos salários e/ou sem renda, esses migrantes foram forçosamente excluídos da possibilidade de obterem moradia que estivesse devidamente enquadrada nas leis das cidades. Este fato ensejou na formação da cidade informal, constituída principalmente por favelas, cortiços e loteamentos irregulares ou clandestinos.

Até o início dos anos de 1980, as grandes cidades brasileiras ainda dispunham de certa disponibilidade de terras urbanizáveis que, com o crescimento intenso, foram rareando. Isso resultou na ocupação cada vez mais recorrente das áreas ambientalmente frágeis, exacerbando o conflito entre urbanização e preservação ambiental. A existência de leis de proteção ambiental, que teoricamente limitariam essa ocupação, e, ao mesmo tempo, a constatação de sua ineficácia, mostram que o modelo tradicional baseado no binômio regulação-fiscalização não é capaz de alterar essa dinâmica, cuja solução deveria estar, mais do que na fiscalização, na mudança dos paradigmas de urbanização, com oferta adequada de moradia para todos nas áreas urbanizadas (BRASIL, 2015).

A autoconstrução em loteamentos periféricos aos grandes centros econômicos passou a ser, de meados do século XX em diante, a forma comum de acesso à moradia pela população de baixa renda, como forma a responder, na limitada medida do possível, não só à falta de teto para morar, mas também à ausência de terra urbanizada, infraestrutura, espaços coletivos e comunitários, equipamentos públicos, em resposta à inação do Estado que desonerava-se assim de suas obrigações (MARICATTO, 1982). A generalização da precariedade habitacional, que assume a forma de favelas, cortiços, loteamentos 
irregulares, palafitas, tornou-se regra em todo o mundo subdesenvolvido, como mostrou Mike Davis em seu livro Planeta favela (DAVIS, 2006), sendo hoje a favela a forma predominante de moradia nos países mais pobres. Essa ausência proposital do Estado ao longo da sua industrialização foi interessante para manter o baixo custo da mão de obra que sustentou o crescimento econômico dos países do Sul. Entretanto, os elevados custos dessa não urbanização tornaram-se um passivo urbano ambiental de difícil solução para seus governos. O crescimento desordenado dos grandes centros urbanos, aliados a processos de urbanização diferenciados acabaram mostrando as diversas faces que uma mesma cidade pode apresentar, dependendo do bairro e da classe social da população que o ocupa. A face mais visível é a existência de duas cidades dentro da cidade, que convivem e coexistem pacificamente, lado a lado: a cidade legal, onde se encontram presentes todos os serviços e infraestrutura urbana, e a cidade ilegal ou clandestina, que se caracteriza pela ausência de normas legais e urbanísticas.

Para Maricatto (2001), estas ocupações informais (favelas, cortiços, loteamentos irregulares) ocorrem geralmente via autoconstrução de moradia, consolidadas em áreas não urbanizadas públicas ou privadas, que não serviam para o mercado imobiliário, ou em locais com alguma especificidade ambiental que as tornam impróprias para o uso habitacional - áreas como encosta de rios, topo de morro, dentro de áreas de preservação permanente - o que causa enormes catástrofes humanas e ambientais, ou até mesmo em casarões e prédios abandonados que são invadidos pela população em busca de moradia. Maricatto (2001) avalia que, apesar dos loteamentos irregulares passaram pelo crivo do poder público municipal, geralmente contém alguma irregularidade: ou o loteador não observou todas as etapas indispensáveis para ocorrer a implantação ou o loteamento foi executado em desconformidade com o que foi aprovado. Em ambas as situações o lote de terra é vendido por preço mais acessível, no entanto, o comprador obtém a posse e não a propriedade; o lote vendido não está devidamente registrado.

Em suma, a cidade legal pode ser identificada com o processo de expansão e de ocupação urbana planejada, amparada por instrumentos jurídicos e práticas políticas legais. É aquela que observa uma determinada ordem, é baseada em um projeto e costuma apresentar a chamada urbanização completa, onde todos os itens de consumo coletivo, de equipamentos e serviços encontram-se presentes. Enquanto que a cidade ilegal está associada ao processo informal de ocupação urbana, o qual ocorre sem qualquer participação do poder público ou de suas instâncias administrativas. O quadro que se estabelece neste estudo é de uma cidade real, que apresenta uma característica peculiar: uma porção legal, muitas vezes abastada com infraestrutura e investimentos públicos e uma cidade produzida espontaneamente, em que parte dela é ilegal, pobre e precária.

Portanto, pode-se induzir que a formalização dos direitos de propriedade tende a apresentar impacto positivo e significativo no rendimento domiciliar e, consequentemente, atenuar os impactos oriundos do 
processo de urbanização desordenado. Em outras palavras, a presença do Estado torna-se fundamental para a melhoria das condições socioeconômicas e a inclusão social a partir da definição e garantia dos direitos de propriedade dos imóveis.

\section{O DIREITO DE PROPRIEDADE POR DOUGLASS NORTH}

Diversos estudos em regiões e países analisaram, nos últimos anos, os efeitos da boa definição, atribuição e segurança dos direitos de propriedade. Besley (1995) limita o vínculo entre os direitos de propriedade e o aumento do bem-estar econômico a três canais: (i) aumento da segurança da ocupação e dos incentivos ao investimento; (ii) custos de transação mais baixos e ganhos com o comércio e; (iii) aumento do valor do ativo como colateral e diminuição da restrição ao crédito (FIELD, 2003a, p. 5). Como Besley (1995), a maioria dos trabalhos empíricos do impacto dos direitos de propriedade formais referese à área rural, baseados na hipótese de haver interesse no investimento na agricultura e nas políticas de reforma agrária. Há alguns trabalhos, entretanto, que analisam programas de regularização de ocupações em comunidades de baixa renda em centros urbanos como, e.g., Lanjouw e Levy (2002), Field (2003a, 2003b, 2005), Field e Torero (2006), Galiani e Schargrodsky (2004, 2007). Além dos impactos econômicos, os programas de regularização fundiária também apresentam efeitos sociais, como, por exemplo, (i) segurança da ocupação; (ii) status social, integração e inclusão social; (iii) gênero; (iv) saúde, educação e fertilidade, entre outros.

A partir da obtenção conjunta com Robert Fogel do Prêmio Nobel de 1993, Douglass North passou a ser referência para o estudo do desenvolvimento das economias no longo prazo. Desenvolveu, entre outros, uma série de trabalhos para entender o papel das instituições na evolução das sociedades, que culminam no livro Institutions, Institutional Change and Economic Performance, de 1990. Numa obra com muitas incursões históricas e algumas inovações teóricas, o autor demonstra como o crescimento de longo prazo, ou a evolução histórica, de uma sociedade é condicionado pela formação e evolução de suas instituições.

Postas essas observações, a escolha de Douglas North como fio condutor para análise neste trabalho justifica-se pelo fato de que o mesmo atribui um peso importante às instituições. Para ele, o direito de propriedade por si só de nada adianta se não houver instituições que o garantam. A análise de Douglass North sobre a relação entre Estado, liberdades e crescimento econômico é o resultado de um longo processo de evolução. Deste modo, o propósito desse item configura-se em destacar os principais pontos da visão de North que são representativos do papel institucional do Estado para resolver os litígios contratuais, como é o caso do direito de propriedade. 


\title{
3.1 ESTADO E DIREITO DE PROPRIEDADE
}

A divisão do trabalho nas economias modernas exige o desenvolvimento de uma estrutura institucional, compativel com a crescente complexidade nas interações entre os agentes econômicos. 0 Estado é caracterizado em North (1989) como fundamento das instituições econômicas em sociedades baseadas em trocas impessoais e complexas, isto é, das sociedades modernas. Essa constatação começa a responder à pergunta sobre os motivos da permanência de direitos de propriedade que produzem resultados econômicos ineficientes. Resulta, então, que o surgimento do Estado transforma o estabelecimento de regras que regulam os direitos de propriedade sem relação necessária com a eficiência econômica.

Para North (1999), os ganhos obtidos da troca estão diretamente relacionados à definição e garantia dos múltiplos atributos que compõem uma dada cesta de direitos de propriedade. Quanto melhor definidos e mais garantidos forem esses direitos, mais eficientes serão as instituições como sistema de incentivos ao crescimento, de acordo com North (1999, p. 21). Em grande medida, os custos de verificação e garantia dos direitos de propriedade podem ser reduzidos, em primeiro lugar, se os vínculos entre os agentes possuírem natureza mais pessoal:

\begin{abstract}
By personal exchange, I refer to a world in which we deal with each other over and over again in small-scale economic, political and social activity, where everybody knows everybody, and where under those conditions, to use a simple illustration from game theory, it pays to cooperate. That is, game theory says that human beings co-operate with each other when they play a game over and over again, when there is no end game, when they know the other parties to exchange, and when there are small numbers. (NORTH, 1999, p. 21).
\end{abstract}

Quando existe uma rede densa de relações sociais, os custos de transação são baixos, mas os custos de produção são elevados. Mas essa não é a caracterização da sociedade moderna, pelo menos o mundo que surgiu com a indústria química alemã, na segunda metade do século XIX. No mundo moderno, ao contrário das sociedades caracterizadas por redes densas de relações entre seus membros, os custos de transação são elevados:

A pure model of this world of impersonal exchange is one in which goods and services or the performance of agents is characterized by many valued attributes, in which exchange takes place over time, and in which there are not repeated dealings. Under these forms of exchange, the costs of transacting can be high, because there are problems both in measuring the attributes of what is being exchanged and problems of enforcing the terms of exchange; in consequence there are gains to be realized by engaging in cheating, shirking, 
opportunism etc. ... As a result, in modern Western societies we have devised formal contracts, bonding of participants, guarantees, brand names, elaborate monitoring systems, and effective enforcement mechanisms. In short, we have well-specified and well-enforced property rights. (NORTH, 1989, p. 1320).

É importante chamar a atenção aqui para a noção de eficiência com que North (1981) trabalha. North (1981) considera como sendo eficiente uma especificação de direitos de propriedade que maximize o investimento privado, na medida em que torne desprezíveis quaisquer externalidades associadas a esses direitos. Essa noção de eficiência é muito distinta da noção neoclássica de eficiência que repousa sobre a norma paretiana de promover melhorias sob a condição de não piorar o estado de nenhum indivíduo na sociedade. North não exige a obediência à norma paretiana, e sim uma configuração de direitos que, ao maximizar a inversão privada, maximize também a taxa de crescimento, ainda que esta configuração piore a situação de algum indivíduo na sociedade.

A relação entre instituições e desenvolvimento econômico pode ser considerada complexa e depende das suas inter-relações com o ambiente institucional, composto tanto pelas demais instituições formais de suporte como pelas instituições informais. Há razões para se acreditar que existe mais de um formato eficiente de instituição que se encaixe no ambiente institucional. Um exemplo são os direitos de propriedade, que podem apresentar as mais variadas formas, sendo a sua eficiência dependente das instituições com que se relaciona. Há casos, também, em que as instituições informais, a cultura da sociedade, impedem que o resultado de determinada instituição seja satisfatório. É importante discutir com um pouco detalhe o conceito de path dependence, fundamental para entender a permanência de direitos de propriedade ineficientes.

\subsection{PATH DEPENDENCE E EVOLUÇÃO INSTITUCIONAL}

Um elemento importante do pensamento de North (1990) resulta do reconhecimento de que as instituições no presente condicionam os futuros desenvolvimentos institucionais. Para expressar esse fato, North (1990) utiliza o conceito de path dependence:

Technological change and institutional change are the basic keys to societal and economic evolution and both exhibit the characteristics of path dependence. Can a single model account for both technological and institutional change? They do have much in common. Increasing returns is an essential ingredient to both (NORTH, 1990, p. 103).

A ideia de path dependence foi elaborada inicialmente com relação à presença de rendimentos crescentes a partir da escolha de um dado padrão tecnológico. Esses rendimentos crescentes levam a uma 
situação de lock-in, isto é, uma situação em que um dado padrão tecnológico se generaliza e consolida, e a mudança de padrão tecnológico se torna extremamente difícil. Por consequência, isso leva ao fenômeno de path dependence, ou seja, o fato de as possibilidades de escolha no presente serem estritamente condicionadas pelas escolhas passadas.

De acordo com North (1990, p. 95), também em relação às instituições se verificam processos de path dependence. Para entender o conceito de path dependence no estudo das instituições, é preciso considerar as causas de path dependence em tecnologias, isto é, o que termina por gerar uma situação de lock-in. Essas causas seriam: (1) custos fixos significativos, provocando uma redução expressiva dos custos à medida que a produção aumenta; (2) efeitos de aprendizagem; (3) efeitos de coordenação, derivados da cooperação entre agentes que enfrentam o mesmo tipo de situação; e (4) expectativas adaptativas (NORTH, 1990).

As instituições novas enfrentam elevados set-up costs, verificam-se efeitos de aprendizagem, derivados do conjunto de oportunidades oferecido pelo quadro institucional estabelecido, juntamente com efeitos de coordenação através de contratos com outras instituições e investimentos induzidos em atividades complementares e, finalmente, expectativas adaptativas, na medida em que o aumento do número dos contratos baseados em uma determinada instituição reduz as incertezas quanto ao futuro daquela instituição (NORTH, 1990).

A definição e garantia dos direitos de propriedade possuem papel fundamental no estudo da história econômica, e nada garante, em função da característica de path dependence no desenvolvimento das instituições, que o quadro institucional em uma dada sociedade evoluirá rumo à maior eficiência. North (1981) cita vários exemplos históricos de direitos de propriedade mal definidos, ou ainda definidos de forma ineficiente, por longos períodos de tempo. Um exemplo é o direito medieval das guildas de pastores de ovelhas na Espanha, as Mestas, de levarem suas ovelhas através do país, inclusive de impedir o fechamento das terras cultivadas a sua passagem. O direito à livre movimentação dos rebanhos teria atrasado, de acordo com North (1981), o desenvolvimento de direitos eficientes de propriedade na agricultura espanhola por séculos.

\subsection{ESTADO E SOCIEDADE}

Também contribui para a relevância institucional do Estado o reconhecimento de que, de acordo com North (1981), a iniciativa das reformas institucionais deve partir com mais frequência dos governos: "... institutional innovation will come from rulers rather than constituents since the latter would always face the free rider problem" (North, 1981, p. 28). Porém, North (1981) atribui explicitamente ao Estado a 
responsabilidade pelo crescimento econômico, na medida em que, na sociedade moderna, cabe ao Estado definir, atribuir e garantir direitos de propriedade:

A theory of the state is essential because it is the state that specifies the property rights structure. Ultimately it is the state that is responsible for the efficiency of the property rights structure, which causes growth or stagnation or economic decline.(NORTH, 1981, p. 17).

North (1990) apresenta os elementos de sua teoria do Estado, vinculando-os diretamente à atividade de definição e garantia dos direitos de propriedade:

A state is an organization with a comparative advantage in violence, extending over a geographic area whose boundaries are determined by its power to tax constituents. The essence of property rights is the right to exclude, and an organization which has a comparative advantage in violence is in the position to specify and enforce property rights (NORTH, 1981, p. 21).

O Estado, caracterizado assim, é para North um agente com objetivos próprios. Para desempenhar essa função (vender proteção e justiça), o governo age monopolizando a definição e a garantia dos direitos de propriedade (NORTH; THOMAS, 1973, p. 97). Como remuneração por esse serviço, o governo arrecada imposto. Essa transação (o pagamento de impostos por parte da sociedade em troca de proteção e justiça, isto é, da definição e garantia dos direitos de propriedade) é vantajosa, na medida em que o Estado possui economias de escala nessas tarefas e, portanto, seria mais custoso para os agentes privados desempenharem essas tarefas por si próprios. Na medida em que essas economias de escala não sejam exauridas, a ampliação das funções de proteção e garantia dos direitos de propriedade aumenta a renda de toda a comunidade, geram uma poupança a ser dividida entre a sociedade e o Estado.

No que diz respeito a como será dividida essa poupança entre a sociedade e o Estado, segundo North (1990), há uma disputa em relação aos ganhos incrementais resultantes dessa troca: o Estado vai procurar capturar o máximo possível da renda adicional gerada, o mesmo valendo para a sociedade. Definido o objeto da disputa entre o Estado e a sociedade, segue-se a questão dos determinantes do comportamento do Estado nessa disputa. Evoluindo como um corpo de costumes não escritos (como na mansão feudal) ou como uma constituição escrita, eles têm dois objetivos: primeiro, para especificar as regras fundamentais da competição e cooperação que irá fornecer uma estrutura de direitos de propriedade (ou seja, especificar a estrutura de propriedade em ambos os mercados de fatores e produtos) para maximizar as rendas resultantes, para o governante. No âmbito do segundo objetivo, para reduzir 
os custos de transação, a fim de fomentar a produção máxima da sociedade e, portanto, aumentar as receitas fiscais provenientes do Estado.

Em relação a esses objetivos, North (1981) observa, em primeiro lugar, que eles não são necessariamente consistentes, pois não necessariamente o conjunto de regras institucionais que maximiza a receita do Estado é aquele que determina direitos de propriedade que maximizam o produto social. Em segundo lugar, existem problemas do tipo agente-principal entre o governante e sua burocracia, e alguma dissipação das rendas de monopólio do governante sempre irá acontecer, inclusive através de coalizão entre os agentes e os constituintes (NORTH, 1981, p. 27). Como um determinante adicional da ação do Estado (mas igualmente importante), North (1981) caracteriza o Estado analogamente a um monopolista discriminador:

\begin{abstract}
The ruler will specify a set of property rights designed to maximize his monopoly rents for each separable part of the economy by monitoring and metering the inputs and outputs of each. The costs of measuring the dimensions of the inputs and outputs will dictate the various property rights structure for the diverse sectors of the economy, which therefore will be dependent on the state of the technology of measurement. (NORTH, 1981, p. 26).
\end{abstract}

O Estado enfrenta, contudo, limites a sua ação monopolista. A esses limites se soma o poder de barganha dos vários grupos sociais para a definição de sua relação com o Estado. Segundo North (1981), o custo de oportunidade de cada um dos vários constituintes será diferente e determinará o poder de barganha que cada grupo tem na especificação dos direitos de propriedade, bem como a carga fiscal em que irá incorrer. Os custos de oportunidade também irão ditar a alocação dos serviços prestados pelo governante na medida em que eles não são bens públicos puros, uma vez que o governante irá fornecer mais serviços para as pessoas com alternativas em relação àquelas com nenhuma.

A determinação de uma dada estrutura de direitos de propriedade e a oferta de serviços pelo Estado estão condicionadas pelos limites à ação monopolista do Estado e pelo poder de barganha relativo dos grupos na sociedade. North considera ainda que: "Constituents may, at some cost, go over to a competing ruler (that is, another existing political-economic unit) or support a competitor for ruler within the existing state" (NORTH, 1981, p. 27).

Aparentemente, ter-se-ia aqui a chave para a questão do crescimento econômico em North: na disputa pelo excedente gerado na sua tarefa de definir, atribuir e garantir direitos de propriedade, o Estado age como monopolista. Todavia, o poder relativo dos grupos na sociedade e a competição enfrentada pelos governantes estabelecem limites à liberdade de extração de excedente pelo Estado, e o Estado se vê obrigado a especificar direitos de propriedade e fornecer serviços favorecendo em maior proporção 
(quando comparados com a receita fiscal gerada) os grupos de maior poder político. Dependendo da natureza desses grupos, os direitos de propriedade especificados não conduzirão à maior eficiência, os custos de transação não serão reduzidos e a estagnação e a decadência serão o resultado. O fenômeno de path dependence torna esta alocação ineficiente uma herança que é transmitida para as gerações futuras.

Esse processo é reconhecido por North (1990) como sendo na prática mais complexo do que a simplificação acima. Como destaca North (1990), a percepção dos agentes da realidade em que vivem também é um elemento importante na determinação do tipo de interação social que realizam e, assim, nos tipos de instituições que se desenvolvem. Essa percepção, por sua vez, é estritamente condicionada pela ideologiaque esses agentes possuem. Ideologia em North (1990), contudo, não possui o mesmo significado que em Marx: não se trata de uma falsificação da realidade, manipulada pelas classes dominantes para a submissão dos dominados. Segundo North (1990), dado que todos os indivíduos da sociedade possuem racionalidade limitada e se defrontam com um ambiente que envolve incerteza, todos se vêem obrigados a desenvolver ideologias, entendidas aqui como modelos imperfeitos de funcionamento da realidade, modelos que não apenas procuram explicar como a sociedade em que esses indivíduos vivem opera, mas também permitem extrair recomendações normativas sobre como essa sociedade deveria operar (NORTH, 1990, p. 23).

Pode-se afirmar que, em North (1990), não se deve esperar que a interação entre o Estado e grupos sociais, que foi caracterizada acima como uma barganha entre receita fiscal por um lado e a especificação de direitos de propriedade e serviços do Estado por outro, se dê em termos necessariamente coerentes com as características sociais e econômicas do contexto em que essa barganha se desenvolve: a ideologia dos governantes (e dos governados) pode levar a equívocos na interpretação da sociedade em que atuam.

\subsection{DIREITO DE PROPRIEDADE E OS CUSTOS DE TRANSAÇÃO}

A análise econômica do direito de propriedade representa a linha de sustentação fundamental dos estudos das diferentes vertentes que estudam a Economia do Direito, entre as quais Mercuro e Medema (1997) citam a Escola de Chicago, a Teoria da Escolha Pública, a Escola Institucionalista e a Nova Economia Institucional. Esta última sendo uma área do conhecimento que releva a importância das instituições como promotoras do desenvolvimento econômico e as considera passíveis de análise.

Em Economia, o trabalho seminal de Ronald Coase, The Nature of the Firm (1937), abordou o tema da propriedade, conhecido posteriormente como "Teorema de Coase". Partindo do conceito de que o que se negocia não são os bens objeto de direito, mas sim direitos de propriedade sobre dimensões de bens, Coase (1937) propõe que, na ausência de "custos de transação", a alocação ou distribuição inicial dos 
direitos de propriedade sobre as dimensões dos bens não terá importância, pois os agentes negociarão a transferência dos bens a custo zero, podendo realocar de modo eficiente tais direitos.

A proposta de Coase (1937), talvez melhor explicitada no seu discurso ao receber o Prêmio Nobel, pode ser desdobrada da seguinte forma: "O mundo real apresenta fricções que denominamos 'custos de transação.' Fricções estas causadas por assimetrias de informação que dificultam ou impedem que os direitos de propriedade sejam negociados a custo zero." Os "custos de transação" são afetados pelo sistema legal e por normas não positivadas, que recaem sobre a alocação dos direitos de propriedade. Oliver Williamson, entre outros, foi um dos principais autores que influenciou a Teoria do Custo da Transação. O trabalho de Williamson foi um aprofundamento das idéias de Ronald Harry Coase (1937), que trata das fronteiras das empresas e das transações em si. Partindo dos estudos de Coase, Douglass North ampliou o seu trabalho, tendo como foco a importância das instituições para o desenvolvimento socioeconômico do impacto no controle dos "custos de transação" e, portanto, na alocação do direito de propriedade. Douglass North (1990) explorou esta dimensão na área macro institucional. North (1992) reduz o grau da abstração de seu discurso para explicitar o que de fato o interessa derivar do conceito de incerteza: os custos de transação. Grosso modo, estes se dividem em dois. Custos de measurement e de enforcement. 0 primeiro relaciona-se à dificuldade dos agentes em conhecer de fato o objeto da transação em curso (NORTH, 1990, p. 29). O ponto crucial aqui está na impossibilidade do conhecimento da qualidade do produto de forma ex ante pelo agente comprador em uma transação; fato que, no limite, pode abortar a troca, anulando possiveis ganhos de comércio.

Os custos de enforcement, por sua vez, referem-seà incerteza que os agentes têm sobre a propriedade do bem a ser trocado (NORTH, 1990, p. 32) e, portanto, relacionam-se a problemas de legitimidade da transação a ser efetuada. A preocupação se volta a transações complexas que envolvem bens consumidos e produzidos ao longo do tempo, e não meramente trocas simples e únicas. Se algum tipo de arcabouço de proteção não estiver presente de forma a minimizar esse tipo de incerteza, veremos que, novamente, as trocas entre agentes não serão possiveis. A partir desses dois conceitos, custos de measurement e de enforcement, North (1990) procura mostrar a dificuldade enfrentada pelos agentes econômicos por conta da existência de incerteza. A partir daí, introduz o conceito de instituições, que será a base de todo o seu modelo. Estas, ao reduzirem os custos de transação, atenuam o problema da incerteza, facilitarão a coordenação econômica e social. Não há nada que garanta, para North (1990), uma evolução institucional que aumente a eficiência das economias.

Em geral, quanto mais completas forem as especificações dos direitos de propriedade, menor será a incerteza, menores serão os custos de transação e maior será o valor do ativo. Observa-se, a partir dos trabalhos de Douglass North, que os custos de transação podem ser reduzidos na medida em que 
os vínculos entre os agentes possuam uma natureza mais pessoal ou existam instituições que facilitem essas interações.

\section{CONSIDERAÇÕES FINAIS}

A questão norteadora da pesquisa foi a de analisar os impactos do processo de urbanização brasileiro relacionados ao direito de propriedade. Em um primeiro momento, associadas às análises realizadas, verificamos indicativos significativos referentes à forma na qual ocorreu a urbanização das cidades brasileiras, causadora de resultados socioeconômicos desastrosos, mais especialmente os relacionados à obtenção de moradia. O fenômeno da urbanização no Brasil, muito superior ao dos países desenvolvidos, registrou um aumento de 7,3 vezes a população urbana. A velocidade que se desenvolveu esse processo faz com que a demanda por moradia seja uma realidade. Autoconstruções, invasões, a luta por espaço para a moradia, são consequências marcantes desse desenfreado crescimento populacional urbano.

Constatamos que os impactos dessa transição rápida e excludente, em virtude da migração rural para a cidade em busca de emprego e melhores condições de vida, reflete-se na exclusão por grande parte da população da possibilidade de obter moradia no mercado formal, em razão da baixa remuneração recebida pelos trabalhadores. Tal fato motivou a formação da cidade informal, constituída principalmente por favelas, cortiços e loteamentos irregulares ou clandestinos.

Após a análise do fenômeno da urbanização, embrião da problemática habitacional urbana do país, partiu-se para a análise do direito de propriedade. A partir do panorama realizado neste trabalho, observou-se ser possível situar contribuições da Economia Institucional sobre o desenvolvimento de políticas públicas referentes à moradia em um plano mais amplo, relacionando-as a literaturas da Nova Economia Institucional, da qual Douglass North é sem dúvida o representante mais destacado.

Desse modo, podemos concluir que o novo pensamento institucionalista, aqui representado com as ideias de North (1990), oferece os elementos necessários para a incorporação das instituições como atores do processo de normatização dos direitos de propriedade, visando reduzir os impactos da urbanização no tocante à moradia. Quanto melhor definidos e mais garantidos esses direitos, mais eficientes serão suas consequências. Porém, devemos ressaltar que os direitos de propriedade, em razão do conceito de path dependence, em nada garantem que o quadro institucional em uma dada sociedade evoluirá sempre rumo a maior eficiência. $\mathrm{O}$ foco de North esteve na influência do grau de proteção da propriedade privada sobre o desenvolvimento dos países. De modo simplificado, percebemos que sua principal recomendação para os países consiste em criarem-se políticas públicas que favoreçam a segurança e a previsibilidade dos negócios, via fortalecimento da propriedade privada e dos contratos. 
Um dos problemas da favelização é também a ausência do Estado no reconhecimento dos seus direitos de propriedade. Ou seja, o papel que as instituições exercem no desenvolvimento econômico é função do Estado na medida em que ele atribui, define e garante os direitos de propriedade na sociedade. Portanto, é razoável afirmar que, com os seus diretos de propriedade definidos e garantidos formalmente, os moradores de comunidades de baixa renda teriam um rendimento domiciliar esperado maior, pois o reconhecimento dos direitos de propriedade aumenta a mobilidade e a capacidade de reprodução dos ativos em favelas.

Ressalta-se que o tema tratado no artigo é árido e por essa razão este estudo está longe de esgotar o tema. Para estudos futuros, sugere-se investigar como e quanto é importante inserir no desenho das políticas públicas o enfoque nos direitos de propriedade como medida de redução dos impactos decorrentes do acelerado processo de urbanização nacional.

\section{REFERÊNCIAS}

BESLEY, Timothy. Property Rights and Investment Incentives: Theory and evidence from Ghana. The Journal of Political Economy, vol. 103, no. 5, p. 903-937, oct. 1995.

BRASIL. Ministério do Meio Ambiente. Sustentabilidade urbana: impactos do desenvolvimento econômico e suas consequências sobre o processo de urbanização em países emergentes: textos para as discussões da Rio+20. Vol 3. Habitação social e sustentabilidade. Brasília. 2015.

CARVALHO, P. F. Repensando as áreas verdes urbanas. Rio Claro: Unesp, Território e Cidadania, 2003.

COASE, R. H. The nature of the firm. Economica, London, v. 4, p. 386-405, 1937.

DAVIS, M. Planeta favela. São Paulo: Boitempo Editorial, 2006.

FERNANDES, E. (Coord.). Direito urbanístico e política urbana no Brasil. Del Rey: Belo Horizonte, 2001.

FIELD, E. Entitle to work: urban property rights and labor supply in Peru. Princenton: Princeton University, julho de 2003a (mimeo).

Fertility reponses to land titling: the roles of ownership security and the distribution of household assets. Princenton: Princeton University, 2003b (mimeo).

Property rights and investment in urban slums. Journal of European Economic Association, p. 279-290, abril/maio de 2005. 
FIELD, E.; TORERO, M. Do property titles increase credit access among the urban poor? Evidence from a Nationwide Titling Program. Princenton: Princeton University, março de 2006 (mimeo).

GALIANI, S.; SCHARGRODSKY, E. Effects of land titles on child health. Washington: Inter-American Development Bank, julho de 2004 (Research Network Working Paper, R-491).

Effects of land titles. Buenos Aires: Universidad Torcuato Di Tella, janeiro de 2007 (mimeo).

INSTITUTO BRASILEIRO DE GEOGRAFIA E ESTATÍSTICA. Censo Demográfico, 2010. Disponível em: $<$ www.ibge.gov.br>. Acesso em: 17 mar. 18.

KOWARICK, L. A Espoliação Urbana. Rio de Janeiro: Paz e Terra, 1979.

LANJOUW, Jean O.; LEVY, Philip I. Untitled: a study of formal and informal property rights in urban Ecuador. The Economic Journal, vol. 112, p. 986-1019, oct., 2002.

MANTEGA, G. Teoria da dependência revisitada: um balanço crítico. Relatório de Pesquisa n² 27, EAESP/FGV/NPP Núcleo de Pesquisas e Publicações, 1997.

MARICATTO, E. Autoconstrução, a arquitetura do possível. In: A produção capitalista da casa (e da cidade) no Brasil Industrial. São Paulo: Alga-Ômega, p.71- 93, 1982.

Brasil, cidades: alternativas para a crise urbana. Petrópolis: Vozes, 2001.

MERCURO, N.; MEDEMA, S. G. Economics and the law; from Posner to post-modernism. Princeton: Princeton University Press, 1997

NORTH, D. C. Structure and change in economic history. New York: W. W. Norton \& Co., 1981.

. Institutions and economic growth: a historical introduction. World Development, v. 17, n 9, 1989.

. Institutions, institutional change and economic performance. Cambridge: Cambridge University Press, 1990.

. Transaction costs, institutions, and economic performance. San Francisco: ICS Press, 1992.

. Understanding the process of economic change. London: Institute of Economic Affairs, 1999.

NORTH, D. C.; THOMAS, R. P. The rise of the western world: a new economic history. Cambridge: Cambridge University Press, 1973. 
OJIMA, R. A produção e o consumo do espaço nas aglomerações urbanas brasileiras: desafios para uma urbanização sustentável. In: Encontro Nacional de Estudos Populacionais. 15, 2006, Caxambu. Anais... Associação Brasileira de Estudos Populacionais, Caxambu, 2006.

ONU-HABITAT - Programa das Nações Unidas para os Assentamentos Humanos. Disponível em: <http://nacoesunidas.org/agencia/onu-habitat/>. Acesso em: 12 abr. 2018.

PORTES, A.; ROBERTS, B. R. Introdución. In: PORTES, A.; ROBERTS, B. R. La ciudad bajo el libre mercado. La urbanización en América Latina durante los años del experimento neoliberal. Buenos Aires: Prometeo Livros, 2005. Introdução, p. 13 - 59.

ROLNIK, R. Estatuto da Cidade - Instrumentos para as cidades que sonham crescer com justiça e beleza. Belo Horizonte: PUC Minas Virtual, 2009.

SANTOS, M. Técnica, espaço, tempo: globalização e meio técnico-científico informacional. São Paulo: Universidade de São Paulo, 2008.

SILVA, H.; MONTE-MÓR, R. L. Transições demográficas, transição urbana, urbanização extensiva: um ensaio sobre diálogos possíveis. In: Encontro Nacional de Estudos Populacionais. 2010, Caxambu. Anais. Associação Brasileira de Estudos Populacionais, Caxambu, 2010. 